\title{
12 Stories on Future-Making in Everyday Practices from Managers in the Creative Industries
}

\author{
Pernilla Severson
}

Stories can rehearse and stabilise particular futures, and in so doing make others absent. Watts 2008, 188

In many ways this book is a reaction to Eric von Hippel's assertions that democratic innovation enables users to develop "exactly what they want, rather than relying on manufacturers to act as their (often very imperfect) agents" and that users can "benefit from innovations developed and freely shared by others" $(2005,11)$. Most of the chapters in the present book respond to this view of innovation with stories of design experiments in which marginalized groups in society participated in alternative kinds of design and innovation. The "Scandinavian collective designer" is the ideal type to ignite and lead an alternative future-making: making other futures possible and present.

This chapter, however, is an interweaving of stories and theories exploring meaning-making and sense-making of innovation and collaboration in everyday practices among managers on different levels in the creative industries entities labeled as IT, design, and media companies. The interviewed managers ${ }^{1}$ are storytellers who inter-

pret the world they experience and sometimes tell stories about how the world should be. Innovation is approached as something integrated in everyday practices, rather than in special and clearly demarcated situations.

Stories are not mirrors of the past. Instead they are what Riessman $(2003,708)$ describes as refracting the past and in that are valuable to research because of the interpretive aspects from storytellers that exist in such a refraction: "The 'truths' of narrative accounts are not in their faithful representations of a past world, but in the shifting connections they forge among past, present, and future. They offer storytellers a way to re-imagine lives (as narratives do for nations, organisations, ethnic/racial and other groups forming collective identities)." In this chapter you will encounter theoryinfused themed selections from arguments based in performed stories in the interviews with regard to everyday practices for creative class people involved in future-making as managers. At the end of the chapter, these stories are applied more broadly by commenting on how they are relevant to this book's main themes. 


\section{Stories on innovation}

The stories on innovation from the more industrious sphere of creative industries are centered on the notion that the future is connected with the past and the present (Watts 2008). When the fourteen managers are re-telling of the ordinary of innovation, it has therefore meant flashbacking approached as one of those "constitutive moments in the reproduction of familiar modes of identification and action within particular locales and imaginaries" (Suchman 2008, 3) and "how future making requires the simultaneous making of relevant histories as a practice intimately enfolded into acts of invention" (ibid., 9).

In these stories on innovation, key events in everyday practices consist of stating resistance to talking about an ordinary day. Nobody wants to be or do ordinary or same as managers in the creative industries. To express and emphasize change and creativity, one has to disassociate oneself from ordinary in the meaning of sameness:

Well, you can't describe an ordinary day, that's impossible. However, I can boil together what could be a representative day. Because we live in an unprecedented time of change, it also means that one day is very mixed between incredible operational activities one minute and in-depth strategic thinking next hour. (Francis)

In flashbacking an ordinary day, a sort of situated ordinariness occurs that guide future-making. It influences what alternative futures are perceived as possible. It also articulates how innovation is always part of, or made part of, an everyday with routines and things that usually occur. An ordinary day is circling around the issue of ontological safety linked to ongoing change and with different strategies to deal with uncertainties. The situated ordinariness becomes achieving a goal rather than certain activities_for example "setting the brand," as manager Cam says.

To deal with changes by not only accepting them but also welcoming them is part of the job of managing future-making within the creative industries. Leadbeater (2002) make a case that an important part of innovation is that it is inherently uncertain and that innovation is made possible to make use of by being open to uncertainty. Latour (2005) makes an argument on uncertainty that there are five sources of uncertainties for what the social is made up of. Both Leadbeater and Latour are embracing uncertainty, but they differ in their views of what insight and action on uncertainties can and should mean. Whereas Leadbeater is arguing for uncertainties as foundation for making innovation, Latour is arguing for uncertainties as base for making a revelation about what the social is made up of. In the stories from the interviewed managers, dealing with change has made possible future-making as both innovating and revealing. Uncertainties are to be managed, but first what they are made up of has to be revealed.

Another story line on innovation concerns that being a manager usually involves being sometimes located in and sometimes dislocated from the workplace. Some of the 
interviewees tell stories about their importance in the company as something that is not always a good thing. It is important to be important for getting things done, but not to be the one standing in the way of people wanting to do things:

It will be difficult to do things unless I'm on track, and that's a bit of a problem. (Mika)

Agency then is ascribed to people and the connecting of managers to others. For Leadbeater (2002) this would imply lacking practitioner autonomy, not maximizing operational diversity. For Latour (2005) this would be revealing the perception of connection of things, of being social: social actors in the interviews map their own social context, a context highlighting the value of being in action, and in connection and signaling "without connection, no action." At the same time these are stories about a sense of belonging, where identity is primarily linked to the company and collaborating with the ones inside the company.

A connected story on innovation, uncertainties, and action relates to the fact that among the managers what is true and/or most important is not valued. Instead these uncertainties probe a relationship to what can be described as catalyst for perceived authentic relevance: the things that make you want to do things and whatever works in a special setting, situation, or location. Jamie argues that the actual truth is not as important as the way to take what makes you want to do things and then you try it. All managers tell the story of that an opinion is better than no opinion and in somewhat way this is based in a story that there are no answers for really complex issues. Nike is involving user innovation as one part of getting an opinion: "There we have some thoughts and ideas to invite them more in the creation. We have done it a few times. ... It is better to get an opinion than no opinion at all." Francis reduces uncertainty by acknowledging it and at the same time to decide on some sort of picture of the future: "No one has the answer to this question, but we must seek the answers to them, we must act on the basis of some sort of picture of the future." Linked to the issue of practitioner autonomy, this self-governing act demands a context where people have the same sort of picture of the future, and where the managers' role is to align and bridge the picturing of the future.

Claims for facts exist for future-making nevertheless concerning different aspects, sometimes creating clear principles for do's and don'ts. Here the growth of technological uptake is a powerful agent in the stories. For Eddy, no complexity exists; the future is knowable and reachable because of the development of the mobile phone market and Eddy's experience in that area: "I'm terribly knowledgeable about the market, of the mobile phone market. I do not think you can argue that mobile phones are not growing. One can argue who is growing and not and how the technology infrastructure will look like. ... It's pretty clear that it will happen." This echoes Suchman's $(2008,2)$ remark that "the techno frontier of cyberspace is imagined to be indefinitely extensible." 
Other managers touch upon complexity, and some state very clearly that navigating in complex processes for the organization puts demands to solve things in the flow of things to be able to deal with the timing issue. In business as usual and in talk about everyday practices, dealing with uncertainties means managing space (being present) and time (at the right time), and in this timing for future-making you can either change your plans as you go along, or making it fit to the present:

The key is to get a flow from concept to function out there, live. ... That's how the whole company's thinking. ... It does not always end how you have imagined it, even during a day. That's why it's a bit we are acting under this principle-because it is impossible to plan. ... There may be new insights; ideas that have emerged that make us change focus. (Nike)

For Cam dealing with uncertainties and timing is rather discussing how the pressing need for "now" and "sooner" is present in development/innovation. In a conversation about change, Cam talks of "a battle of time." Cam also touches upon timing of raising awareness in the organization and of the future, by showing the uncertainty and at the same time making people being comfortable with that uncertainty. Cam brings forward that a lot of business development has been "too far into the future."

For Mika there is an experience of innovating too late and therefore a changed temporal attitude of doing future-making now: "When do you start to innovate, or, when do you start creating new business development, product development? You do this, when the old one starts to fail-you do not do it in good times." This can be contrasted with Eli's story of the future as something way into the future: "Future issues are seldom so urgent that they need to be solved in seconds. ... And then we have of course the bigger issues for the future. ... they're not subject to any five-minute discussions." A sense of urgency is crucial to stories of change or innovation, and it is linked to economic aspects: to survive as a company you need a viable business model.

Beside flashbacks of daily future-making there are stories from the past among the managers. Making sense of future-making comes from experiences from the past and attitudes toward what will and can happen and perceptions of power that influence future-making. Looking back creates inner confidence, especially if you set your mind on remembering and learning from history. An aspect of this is efforts to manage future-making by history. Francis sketches during the interview, visualizing historical time lines and different key driving forces influencing the company. The sketch on the whiteboard eventually becomes a map of how to manage the future. Overall, Francis is excited about all the changes: "What you and I are talking about is very interesting." Billie tells a story of meaning-making and says "It has become quite clear what possibilities there are." Experience creates security about what future-making is possible. Billie says things like "We could probably not, at least not me, fully articulate what this change would mean, for example, in 2001." Back then the future was attached with strong negative emotions, in Billie's words that it was a "stupid fucking future." 
For Cam, flashbacking is a way to navigate through history in a comprehensive way and to go back to the "origin." Cam declares that one "must create a memory" and that one must learn from mistakes. Cam goes on to say that documentation is important: "Apply it to more areas and we will remember it." This indicates a strong perception of getting documentation of what happened and why, as part of the job as manager within the creative industries: managing future-making also includes managing history-making.

Local aspects are important in the stories, but global aspects are also present. According to Mika, "the media industry is no longer agenda setting in its own sector as much as before." Changes in the world, on a global level, is adding complexity when one's own business is changing and when power relations change between businesses. Dealing with these external factors is an internal matter, articulated by Cam as "Our biggest competitor is ourselves.". In this line of thinking, the organization's mental frames of how to approach and create the future in relation to the changes in the world is spoken in metaphors of a battle; a competition. Managing future-making means managing how changes are perceived and infuse agency in how to handle the future.

\section{Stories on collaboration}

The managers' stories of the everyday making of innovation include accounts of collaborating with people in various ways. In these stories of collaborating with people, collaborating with users are not made very present in the way von Hippel argues that democratic innovation can and should happen. Leadbeater and Miller (2004) claim that creativity and innovation are found in the power of self-organizing Pro-Ams (professional amateurs), supercharged by the Internet. The stories from managers within the creative industries rather portray the people one is collaborating with as professionals and where these professionals are to be found and made contact with in networks. And in these professional networks the industrial logic prevails as norm. Being a manager is belonging to the creative professionals, managing the super-creative core, where the creatives are attributed according to added economic value. The manager's role is to align creative autonomy with industrial logic. Collaboration is made best with sharing the creative ethos and its economic connotations. Involving oneself in collaboration with others not sharing this creative ethos means bringing forward an articulation of an internal class struggle.

For managers an individualistic mode of working is not possible. Collaboration is based on hierarchical power and/or linking of competences. Key activities for the storytellers as managers are organizing people and making people comfortable. Collaboration is addressed as essential. Francis says "We are totally smoked if we do not cooperate." When asked about collaboration, René uses the metaphor of an ecosystem to illustrate a change from doing everything yourself to doing things together: 
We notice that our industry is changing. Previously it was very ... one should do everything oneself. But now it's a lot of talking about these ecosystems. And it's not just talk that one is talking about an ecosystem, but what is happening is that it is very important that you are in a context, in a region actually. I find that very interesting.

Here collaboration is made meaningful as being something linked to certain actors, competences, and values in a region. The story of clusters and their value to regions is made present.

The main focus in stories on collaborating for innovation is the managing of the creatives in the company, and in the contact-making and collaborating with customers (sometimes mentioned as partners). Collaborating with academia for future-making together is present by me making it a question demanding an answer, and then academic collaboration is linked to the customer-partner relationship.

Stories on the managers collaborating with the creatives highlight the interplay including different human aspects that is demanded: the creativity aspect, emotive aspects, and the process and goal of improving things that ease the relationship. The closest and most important collaboration that the managers are involved in is the relationship with the creatives within the workplace. When asked what is most rewarding about the work, Mika answers "I usually say that what is the best with this job, it's the people." For Jamie it is the people linked to a creative process: "Design discussions are always fun. It is a combination of unleashed creativity ... and the opposite, must decide what to do." For Mika, "the hard part is not coming up with stuff; the hard part is to organize them, create opportunities and viability in-to carry out projects is absolutely the hardest." When asked about what is the most challenging thing to deal with in general in work, Alex says "to make people work along together, the interplay between people" and adds the tricky question of balancing work and life: "How do you do when you try to make life and work work for a guy who really only wants to be on parental leave?" Making people comfortable in this process is key and concerns many different things:

We can go through it on the board there, then we follow up: what has been done and not done? ... It can be anything from that it's cold ... or the coffee tastes bad. It can be very small improvements that make people feel better. ... At the same time it may be to question the way we work, or purely technical stuff. ... That's the kind of things we're trying to sift out. (Nike)

An interesting part of collaboration for innovation for managers in creative industries is relating to and working with higher management, whose failure to understand digital development can be problematic for a manager:

It's very, very old thinking and structures. ... In management, there are people who actually do not have any clue of what digital is. ... I've sat in meetings where I was asked. ... Can you change in a blog post after you have published it? I mean, seriously! I think it would be like if you were in the car industry and so you sat in a meeting with the management team and it's someone there who asked-that automatic transmission, what is that thing? (Gill) 
Another significant collaboration that the managers are involved in is the relationship with the customers. For Kim, collaborating is a part of the company-customer relationship: "Without close cooperation with our customers, we have no assignments: it is that simple!" Robyn answers the question about what is hardest to deal with this way: "When it is difficult to have a constructive dialogue with the customer, it is, well, ... to handle, what you feel as a person, as a human." One characteristic of collaboration with customers is the meeting, which involves aligning and bridging in a communicative setting. There are different expectations of what a meeting can lead to, and the norm for managers is to avoid involvement in meetings that do not lead to futuremaking in the sense of creating viability of the company. In the interviews, meetings were spoken of as a way of life, a responsibility, and a possibility. For Cam, meetings are linked to a professional role in which "visibility is enormously important" and you must "practice what you preach." For Kim, meeting people is a big part of what work consists of: "computer, meetings, telephone, or traveling to meetings." Some meetings are planned; others are unplanned. For René, planned meetings with customers are particularly important:

We give, actually, an offer at the meeting, where we say what we could do for you. Then the goal is also to have the right decision makers there with the customer, so that we more or less can lock the transaction at the meeting so that there will be no postponement.

All the managers valorize meetings as opportunities for innovation and collaboration. Jamie says that you never know what the next meeting can result in, but that meeting people almost always yields something: "It really works!" For Mika, meetings with the outside world are crucial for "being in the eye of the storm." Meetings usually are assessed for their business value. Here the valorization of connecting becomes visible, and the good meetings are the ones thought like to contribute to a company's viability.

"It's also an issue of time," says Mika. He/she continues:

I participate in really a lot of meetings. There, somewhere, if I realize that this meeting will not result in anything-even if I become smarter somewhere of it. ... My company will not be much happier for it if I do not make a turnover somewhere. Then I think there is a profit in the meeting anyway, it is not like that, there is a huge profit, but we're really in a situation where we need to find new business. (Mika).

Meet with people simply in order to chat can also be seen as valuable-if it is in the workplace. "I set aside time just to chat," says Toni, who adds that small talk may involve emotions: "The feeling, how it feels, purely spontaneous."

In the stories on collaboration for innovation where otherness is involved, it is spoken of as collaborating with some "others" is easier than with other "others". Gill comments that he/she finds it relatively easy to work with a certain company because "They understand what we are doing." Academia's part in this is in the stories linked to the possibilities of method, financing, and credibility. Collaborating with academia 
is spoken of as a marginal activity, where one's participation is not always paid for and is also associated with hesitations because of academia's tradition of supporting non-commercial ideal. Cam wants to create a "method" as a possible common ground, achieving understanding and competence between both theorists and practitioners. For Kim, "the research that we are interested to engage in is close to commercialization." Financing influences collaboration with academia for innovation, where the research approach is desirable also because of its credibility:

Going forward with this EU money is something that is becoming increasingly important for companies. ... This will take you automatically to cooperate more with the academic world. Then it's good to have an academic world because you need the research approach to the whole, a company never does research. You do not get the credibility by just being... Sometimes you want to have a study you can go back to. (René).

For Kim, hesitation concerns an experience of academic collaboration as something not always paid for and Kim also states that this kind of collaboration is and should only be a small part of what a company does: "At best, we have the cost of such projects. It is not something you can build a business on." Kim says that funding is mostly "guided a lot to universities to pay their salaries." Kim speaks of the European Union as a "hassle factor" with "a mammoth job to work with accounting." Managers say that they are working for free in research projects. The discourse is usually the other way around, that companies exploit academic research as free labor, not that companies are being exploited in research projects with academia. This is a contrast to what other researchers point to (see, for example, Weber 2004). For Eli, collaboration with academia sometimes holds disappointment: "We experienced that one often on a politically symbolic level was interested in cooperation and change, but not when it came to the crunch." Yet another disinclination concerns a perception that academia is supporting non-commercial ideals (which for other managers are seen as the raison d'être of universities) such as striving to enhance the development of open-source software. When asked whether he/she wants to add anything about collaboration with academia, Toni says:

I do not see that commercial cannot be artistic or not indie. I can see a bit as we. ... First and foremost for me as a manager. I want it to go well. I want us to feel good and produce good stuff. But then in the long run, it remains artistically even though it is commercial. Then you do not have to get rich of it. But show me the indie guy who does not like to get paid for just being able to sit and....

In the making of creative industries, history starts with art (Hartley and Cunningham 2001). But here art becomes the classic friction between art and commerce. The relationship between capital and creativity becomes a tension to what degree the creative practices should be industrious. The stories from the managers embody this. 


\section{Applying these stories more broadly}

The ability of managers in the creative industries to exert hegemonic power in futuremaking should not be overlooked or underestimated. They can and do routinize futuremaking according to experiences, perceptions, and ideals. Days are not the same, but they aren't too different either. The drawback of the firmness of situated ordinariness is that not all uncertainties are revealed, just some-especially the ones you can deal with. Technology and economy are perceived as hard facts that set the frameworks for what futures are possible to make. Perceived authentic relevance is also created, insofar as future-making is seen as primarily something happening within the company and managers, not co-workers or users, are seen as catalysts for innovation. Managers fit new collaborations into earlier experiences and perceptions, reproducing a commodified collaboration as primary goal. The rationale for collaboration is that it is to make the future knowable and possible to create according to one's needs. In future-making, common goods are downplayed in relation to business logic, because managers choose what uncertainties and/or complexities to accept and because managers decide what is counted as memory, as method, as useful, and as difficult.

The valorization of future-making and the valorization of collaboration show traces of iteration (Suchman 2008). In the managers' stories, business and profit always come first, where creativity, innovation, and design from users and/or researchers constantly is an issue of if one can afford that collaboration. Connections and collaborations are commodified in an industrial perspective. This doesn't mean that the stories from the manager's only are limited to being narrations from a marketization perspective. Stories can be about things being hard, fun, rewarding, and not always based on aiming for profit. But decisions on actions on how to create futures for the company can never be solely based on this, whether it being looking for pleasure and/or more or less linked to democratic hopes. In the stories from managers in the creative industries democratic aspects are so marginalized that they are virtually invisible. The creative class struggle becomes a separation of the private and public where managerial work represents supervising that this boundary is maintained.

\section{Note}

1. In all, 14 people at ten companies were interviewed. Most of the companies were located in Malmö, but some were in Karlshamn and some were in Karlskrona. The companies were in various IT, design, or media-oriented sectors, and were connected to the cluster initiative Media Evolution. The individuals interviewed were managers on different levels. The interviews were based on 1-2 hours of conversations structured around the themes of everyday activities at work, the future, challenges, and collaboration. 


\section{References}

Hartley, John, and Stuart Cunningham. 2001. Creative Industries: From Blue Poles to Fat Pipes. In The National Humanities and Social Sciences Summit: Position Papers, ed. M. Gillies. Department of Education Science and Training, Canberra.

Latour, Bruno. 2005. Reassembling the Social: An Introduction to Actor-Network-Theory. Oxford University Press.

Leadbeater, Charles. 2002. Innovate from Within: An Open Letter to the New Cabinet Secretary. Demos.

Leadbeater, Charles, and Paul Miller. 2004. The Pro-Am Revolution: How Enthusiasts Are Changing our Economy and Society. Demos.

Riessman, Catherine Kohler. 2003. Narrative Analysis. In The Sage Encyclopedia of Social Science Research Methods, ed. M. Lewis-Beck, A. Bryman, and T. Liao. Sage.

Suchman, Lucy. 2008. Striking Likenesses to Difference. Paper presented at annual meeting of Society for Social Studies of Science, Rotterdam.

von Hippel, Eric. 2005. Democratizing Innovation. MIT Press.

Watts, Laura. 2008. The Future Is Boring: Stories from the Landscapes of the Mobile Telecoms Industry. Twenty-First Century Society 3: 187-198.

Weber, Steven. 2004. The Success of Open Source. Harvard University Press. 